\title{
A APURAÇÃO DOS LUCROS PARA DECISÕES ADMINISTRATIVAS
}

\section{JOEL DEAN}

Em época de inflação, compensa à emprêsa determinar - lucro econômico real, além do contábil. Quais os méritos e limitaçôes dos métodos que, para êsse fim, tem o administrador à sua disposição?

De acôrdo com as diferentes finalidades a que se destinam, devem os lucros ser medidos de formas diversas. A espécie de apuração exigida para grande parte das decisões administrativas não é dada pela demonstração convencional de lucros. e perdas. O "Bureau of Internal Revenue", os acionistas e os bancos exigem tipos diversos de informações e também, em geral, demonstrações de lucros e perdas que atendam a diferentes requisitos. Ademais, a administração da emprêsa, para tomar decisões, faz exigências especiais da análise do lucro; e a demonstração de lucros e perdas usada pelos administradores obedece, comumente, mais aos conceitos da análise econômica do que às convenções do fisco. Há, ainda, muitos ádministradores que não estão satisfeitos com a demonstração de lucros e perdas obtida por meio dos métodos convencionais de contabilidade, por julgarem que suas decisões poderiam situar-se em plano mais elevado se essa demonstração correspondesse, mais de perto, aos propósitos da administração.

JOEL DEAN - Professor da «Graduate School of Business» da «Columbia University».

NOTA: Este artigo é reproduzido sob autorização e traduzido de «The Accounting Review», vol. XXVI, n. ${ }^{\circ}$, abril de 1951. 
Este artigo tenta examinar, do ponto de vista da administração, os tópicos da apuração de lucros que, a nosso ver, têm sido os pontos mais importantes de desacôrdo entre economistas e contadores: (1) o significado da depreciação; (2) o tratamento das perdas e ganhos de capital ; e, talvez o mais importante atualmente (3) o nível-base de preços para a avaliação do ativo (ou seja, custo atual versus custo histórico). Alguns comentários introdutórios sôbre a natureza do lucro e a influência de acontecimentos futuros nos valores presentes servirão para esclarecer as controvérsias.

\section{A Natureza do Lucro das Emprêsas}

O futuro tem papel preponderante nestes três tópicos da apuração de lucros, não só em relação aos valores econômicos, como às decisões de negócios. Os economistas consideram o futuro como a fonte básica do valor presente do ativo e o homem de negócios reconhece que, para suas decisões, o passado é irrelevante, exceto como "preditor" do futuro. O contador porém, encontra aqui um problema: esforçando-se por manter "padrões de realidade" fidedignos e conservadores, prefere relatar fatos históricos e evitar especulações sôbre o futuro.

Para o contador ortodoxo, o lucro líquido é, em essência, um relato histórico do passado. Para o economista, o lucro líquido é, em essência, uma especulação sôbre o futuro. Todos sabemos que nossos rendimentos flutuam através dos anos, aumentando com a prosperidade e à medida que nossas habilidades crescem, e diminuindo com a depressão e a velhice. Sabemos que podemos fazer empréstimos que resgataremos com rendimentos futuros e que devemos economizar para nossas dificuldades no porvir. Estas expectativas governam o montante que podemos gastar no presente. Esta quantia pode ser considerada como o nosso rendimento para o con- 
sumo de bens, neste momento. Em têrmos econômicos, determinamos o valor atual do capital de todos os nossos ganhos futuros e gastamos, neste ano, como rendimento, uma prestação equivalente a uma anuidade daquele valor. As sociedades anônimas têm vida eterna, por isso que seu lucro líquido pode ser medido como a importância máxima que é possível distribuir em dividendos (teòricamente, desde o momento presente até o futuro indefinido), sem diminuir a lucratividade da companhia. Assim, o conceito se refere à preservação do capital real dos acionistas. Logo, para estimar o lucro, é preciso que se faça um prognóstico de tôdas as mudanças da procura, dos processos de produção, dos desembolsos para operação da emprêsa, das receitas e das mudanças de preços (a fim de estabelecer fluxos de numerário em têrmos de poder aquisitivo constante). E preciso um orçamento de caixa (ajustado para poder aquisitivo) que prognostique o futuro mais distante. Se isto fôsse possivel, poderia ser feito um plano de empréstimos e investimentos que permitisse um pagamento anual de dividendos equivalentes ao consumo uniforme de bens, neste momento, que aqui entendemos como o índice de lucro da firma.

Este conceito de lucro de emprêsa é um ideal inatingível, mas demonstra a importância dos fluxos futuros na apuração do lucro e é o árbitro certo para escolha do tratamento contábil mais exato de custos e receitas. $\mathrm{O}$ conceito de lucro do contador, assim como êste, requer, para sua apuração, uma consolidação de transações datadas de desembolsos e entradas de numerário. Há, porém, uma diférença : o contador usa transações passadas ao invés de futuras. (1)

O contador apura o lucro achando a diferença entre o patrimônio líquido no princípio do ano e o patrimônio líquido no encerramento do ano. $\mathrm{O}$ ativo inclui os desembolsos que foram feitos para o ativo imobilizado (imóveis e máquinas) e o ativo realizável a longo prazo (financiamentos e investimentos a longo prazo), além do ativo realizável a curto prazo

(1) o economista considera irrelevantes os custos históricos que não podem, numa dada situação, ser recuperados. Estes, entretanto, não são desprezados pelo contador. 
(títulos fàcilmente negociáveis, estoques e contas a receber), do ativo disponível (caixa e depósitos bancários à vista) e das contas de resultado pendente (despesas pagas antecipadamente). Do total, êle deduz alguns desembolsos futuros - o passivo exigivel a longo e a curto prazo, e também, às vêzes, as provisões para contingências. Deduz também parte da importância que foi gasta no ativo imobilizado e diz que aquela parte representa a fração do custo original que já foi colocada na produção de estoque e, conseqüentemente, de numerário. $\mathrm{O}$ ativo total, menos as reservas e o passivo, constituem o patrimônio líquido, isto é, a mudança de ano para ano na qual está o lucro anual.

O balanço contém, às vêzes, contas intangíveis de ativo, tais como fundos de comércio e patentes que, nominalmente, são antecipações do futuro. Porém, sua avaliação nos livros não está ìntimamente ligada a expectativas. Estas contas têm sua origem nas compras de marcas, mercados ou patentes e refletem os montantes pagos. Para ser conservador, o contador geralmente prefere amortizá-las tão ràpidamente quanto os lucros o permitam. $\mathrm{O}$ fundo de comércio, no balanço de uma nova sociedade anônima, pode representar, ou os lucros do promotor, ou "ações diluídas". A medida que os mercados. vão ficando estabelecidos e começam a entrar lucros, o fundo. de comércio é amortizado. Assim, o fundo de comércio teórico é amortizado à medida que se vai efetivando o fundo de comércio real.

O balanço do economista tem uma interpretação bem diferente, pois é uma tentativa de agregar os lucros que advirão, no futuro, do patrimônio atual da firma. Cada ativo possui lucratividade própria. $\mathrm{O}$ valor desta lucratividade é difícil de determinar, mas, certamente, não é menor do que o preço que se pode obter, no mercado, por êsse mesmo ativo. $O$ valor dos ativos, em conjunto, é, geralmente, maior do que o valor

(2) Assim, embora o contador não derive o lucro inteiramente dos: custos passados, limita as especulações sôbre recebimentos futuros de caixa ao absolutamente certo; as previsóes quanto a desembolsos futuros são, às vêzes, menos rigorosas, como, por exemplo, quando incluem provisões para contingências. 
dos ativos considerados separadamente. Este valor adicional depende da existência de uma organização já em funcionamento, com pessoal treinado, boas relações estabelecidas no mercado e liderança efetiva. (3) Pode ser chamado de fundo de comércio, mas é inteiramente diferente da maioria das espécies de fundo de comércio contábeis. O importante, aqui, é que o balanço do economista provém inteiramente das expectativas de lucro, enquanto que o balanço contábil pode ser tido como o instrumenio básico para o cálculo do lucro contábil. (4)

Como já dissemos, as incertezas que se acumulam a cada passo, neste método, tornam-no adequado apenas para as estimativas mais gerais de lucro. Entretanto, êle pode servir de indicação quanto a "certos" e "errados" nas práticas contábeis para análise do lucro.

Ainda que contadores e economistas comecem de pontos de vista bastante diferentes, na apuração do lucro, poderiam, por definição, chegar a estimativas iguais, mas isto só ocorreria numa economia estacionária, em que os preços fôssem estáveis e a concorrência assegurasse que o custo seria uma boa medida de valor. No mundo real de negócios, de guerras e de inovações tecnológicas, as estimativas de lucro das emprêsas feitas por contadores e economistas são tão diferentes quanto seus propósitos e métodos. Ambas as espécies de apuração são importantes para a administração, mas substituir uma pela outra é mais ilusório do que geralmente se supõe.

\section{Depreciação}

O tratamento da depreciação é importante neste conflito básico. Apenas durante os últimos cinqüenta anos é que a de-

(3) Quando o valor das partes excede o do total, é, òbviamente, tempo para liquidar.

(4) As cotações do mercado de ações estão, em geral, mais em conformidade com as noções de expectativas de valor do economista, do. que com as avaliações históricas do contador. $O$ valor de mercado de uma ação não está lògicamente relacionado ao seu valor contábil e é, comumente, bem diferente dêle. 
preciação tem sido aceita como dedução ao lucro. A medida que os homens de emprêsas compreenderam que deve ser feita uma provisão para a reposição futura do equipamento, acharam necessário desenvolver um tratamento contábil relativo à reserva de depreciação. A insistência do contador de que a reserva fôsse relacionada ao custo original em vez de ao custo de reposição - que é comumente muito diferente - fêz com que a depreciação contábil tivesse utilidade econômica completa, sòmente sob as condições hipotéticas simples de preços estáveis e obsolescência previsível.

O objetivo da depreciação em contabilidade é apropriar à produção o custo total do equipamento, durante o período no qual será usado. (5) A finalidade é garantir que as receitas equivalentes ao custo original sejam, em vez de distribuídas como dividendos, devolvidas ao ativo, em forma de mais equipamento ou dinheiro. Não é relevante para êste problema que o moñtante, que é assim retirado aos dividendos, seja realmente suficiente para a reposição. Esta, de acôrdo com os contadores, não tem relação com a apuração dos lucros.

Para os economistas, há duas espécies distintas de despesas de depreciação. A primeira é o "custo de alternativa" ("opportunity cost") do equipamento, isto é, a alternativa mais lucrativa que é perdida porque o equipamento foi pôsto no seu presente uso. (6) A alternativa no uso de um ativo por um ano pode ser a venda dêsse ativo no princípio, em vez de no fim do ano. $O$ custo de alternativa poderia, então, ser medido

(5) Raramente é a vida útil do equipamento tão longa quanto sua possível vida física. Quando o equipamento é substituído, porque está obsoleto, muito antes de estar fìsicamente desgastado, algumas firmas fazem dois lançamentos: um para deterioração, que é determinado pela estimativa da vida física, e outro para obsolescência, determinado pela vida econômica, que preenche as deficiências do lançamento para deterioração física. A maioria das firmas não distingui os lançamentos para estas duas causas de retirada, mas simplesmente lança a depreciação para um período mais curto, determinado pela «vida da obsolescência».

(6) Este é, às vêzes, chamado «custo do promotor» (user cost). Para uma descrição das diversas espécies de custos do promotor, vide W. A. Lewis, Overhead Costs, New York, Rinehart \& Co. Inc, 1949, pg. 4. 
pela queda do valor do equipamento durante o ano. Esta redução de valor residual, que mede a perda de capital resultante de se adiar e transferir a substituição do equipamento por um ano, produz uma estimativa de custo de depreciação que é bem diferente da depreciação em linha reta feita para um determinado ano. Por exemplo, é comum lançar como depreciação anual um quinto do custo original de um automóvel. Entretanto, o declínio em seu valor residual durante o primeiro ano está, normalmente, mais perto de $40 \%$ do que de $20 \%$ do custo original. Este valor residual năo tem, inerentemente, relação com o custo; assim, durante alguns anos do após-guerra, se elevou, produzindo, do ponto de vista econômico, custos negativos de depreciação.

O custo de alternativa de depreciação depende da natureza da alternativa. Manter o equipamento inativo e guardá-lo para anos futuros pode ser uma alternativa; ou é possível que não haja usos alternativos em outro lugar ou tempo e, assim, não há custo real em tê-lo na função presente. Uma reprêsa hidrelétrica é, talvez, um exemplo desta espécie de investimento especializado e imóvel. O custo econômico do uso do equipamento por um ano, de qualquer modo, nada tem a ver com os dois fatôres importantes da depreciação contábil, ou seja, o custo original e o resíduo eventual do equipamento.

A segunda espécie de custo de depreciação é o esgotamento de um ano de vida aproveitável. No caso da reprêsa, em que não há custo de alternativa, a vida útil futura (que mede seu valor para a firma já em funcionamento) está, não obstante, continuamente se esgotando. Para preservar o capital do proprietário, uma parte suficiente dos lucros brutos da reprêsa deve ser economizada e reinvestida em empreendimentos igualmente lucrativos, talvez numa reprêsa de substituição. O montante desta espécie de depreciação econômica não é determinado pelo custo histórico do equipamento. É melhor medido pelo valor de reposição de equipamento que produza, no futuro, rendimentos equivalentes. Esta espécie de depreciação não é um custo ; o custo foi incorrido quando o capital foi imobilizado originalmente. Trata-se, ao invés, de um ato de poupança, e o montante a debitar cada ano é um problema financeiro 
relacionado às tendências passadas, presentes e futuras dos lucros brutos, bem como às expectativas do nível de preços. Ambos os conceitos econômicos de depreciação são importantes para a administração. O primeiro é necessário para a solução dos problemas oriundos das atividades lucrativas; o segundo para os problemas financeiros da preservação e administração do capital. Em nenhum dêles, entretanto, o custo original toma qualquer parte nas estimativas.

\section{Tratamento dos Ganhos e Perdas de Capital}

Os ganhos e perdas de capital podem ser definidos, em sentido lato, como as mudanças não antecipadas do valor da propriedade, em relação a outros bens existentes no momento, isto é, refletem uma mudança na antecipação que alguém faz da lucratividade da propriedade. (7) As flutuações de preços no mercado de ações são, quase tôdas, desta natureza.

A "propriedade" deve ser aqui interpretada em sentido lato, a fim de incluir habilidade administrativa, estrutura da organização, marcas e boas relações estabelecidas no mercado. Todo o ativo que compreende o valor da firma é vulnerável a essas. mudanças. Por exemplo, o valor do dinheiro em caixa deteriora, na inflação; as contas a receber são prejudicadas por impontualidades não previstas nas reservas para devedores duvidosos; o estoque está sujeito a incêndio, inundação, quedas de preço e concorrência de substitutos; o valor das instalações da fábrica é reduzido quando concorrentes instalam equipamento novo, mais eficiente; e as patentes podem tornar-se inúteis por uma decisão dos tribunais. A lista de possibilidades é imensa.

(7) A definição fiscal não usa êste conceito de ganhos de capital como sendo inerentemente inesperados. Porém, as definições que se baseiam na evidência, como, por exemplo, os aumentos no valor de mercado, são essencialmente equivalentes $\mathbf{E}$ difícil, em princípio, conceber um ganho de capital que nāo seja caprichoso, uma vez que o valor do capital é baseado em lucro previsível. Da mesma forma, as perdas são claramente inesperadas, uma vez que ninguém realiza um investimento na expectativa de uma perda. 
Estas são perdas de capital que, numa sociedade em expansão, são provàvelmente maiores, no total, do que ganhos de capital. Muitos dêstes riscos podem ser obviados pelo estabelecimento de provisões e reservas ou de taxas altas de depreciação. Quando uma administração conservadora faz provisões e reservas em excesso, a diferença aparece, eventualmente, como ganhos de capital.

Uma boa diretriz contábil a seguir com relação a perdas e ganhos de capital é evitar lançá-los, até que se transformem em dinheiro por meio de compra ou venda do ativo, uma vez que não se sabe, até então, qual o seu valor exato em dólares. (8) As vêzes, são feitas importantes reavaliações para menos, quando o valor aparentemente desapareceu; mas a experiência disciplinadora do período de 1929 a 1932 eliminou virtualmente a prática de reavaliações para mais, acima do custo original.

Esta diretriz contábil de não reconhecer perdas e ganhos de capital até que sejam transformados em dinheiro faz surgir o problema do tratamento contábil adequado para receitas provenientes destas reavaliações, na demonstração de lucros e perdas. Muitos dos itens estão relacionados a perdas e ganhos de capital dos anos precedentes. Os contadores não estão de acôrdo sôbre se a transação real de numerário deveria ser debitada contra o lucro ou contra os lucros suspensos. (Para discussão da matéria, vide Accounting Research Bulletin 32, American Institute of Accountants). Porém, para alguns tipos de perdas e ganhos de capital, como por exemplo, a perda na venda de maquinaria não depreciada, tem sido comum refazer-se as demonstrações do ano ante-

(8) As exceções a esta regra são: (1) a avaliação do estoque ao preço de custo ou ao preço de mercado - dependendo de qual dos dois seja o mais baixo - regra conservadora que exige reavaliações para menos durante a deflação (quando o preço de mercado pode ir abaixo do custo de estoque), mas não reavaliações para mais durante a inflação; e (2) a avaliação ao preço corrente de mercado, informação que é fàcilmente encontrada nos jormais. Porém, a aparente precisão que parece garantir estas exceções é, freqüentemente, ilusória como medida, não só de valor de liquidação, como também de poder de lucratividade do ativo. 
rior, permitindo um tratamento adequado para as perdas e ganhos de capital realizados.

O tratamento dado aos relatórios financeiros para as? I : e ganhos de capital não é matéria que interesse aos econo mistas (desde que os relatórios sejam explicados). Os economistas estão preocupados com o futuro, não com o passado. O importante é que ganhos e perdas de capital podem, comumente, ser previstos, com alguma antecedência, antes de serem transformados em dinheiro. (9) Uma administração realista deve manter uma espécie qualquer de balanço, ainda que êste seja apenas uma estimativa que contenha previsão quanto a surprêsas, muito antes que venham a tornar-se suficientemente exatas para serem aceitas pelos contadores. Por exemplo, se os preços devem ser determinados com o objetivo de possibilitar uma taxa "razoável" de retôrno ao investimento realizado, deveriam refletir perdas e ganhos de capital projetáveis, se bem que ainda não transformados em dinheiro. De outra forma, uma taxa de retôrno a ser alcançada, baseada num valor de capital histórico "de fato", mas, não obstante, fictício, pode levar a desagradáveis surprêsas posteriores, oriundas das diretrizes de preços que dela proviriam.

\section{Custos Correntes versus Custos Históricos}

Ao apurar o lucro, os contadores, em geral, lançam os custos em têrmos do nível de preços ao tempo da compra - lançando o desembôlso histórico - e não em têrmos do nível atual de preços. Para isto, dão várias razões: (1) porque os custos históricos produzem uma apuração mais acurada do lucro; (2) porque os custos históricos são menos passíveis de discussão (mais objetivos) do que o cálculo do valor presente de reposição; (3) porque a função do contador é registrar a história, seja ela relevante ou não para os

(9) Accounting Research Bulletin 24 regula o tratamento a ser dado a intangíveis para estas operações. 
futuros problemas econômicos ou de negócios, mas presumìvelmente na esperança de que o seja. (10)

Os argumentos sôbre a contabilidade de custos históricos têm-se desenvolvido por décadas, mas nunca foi o debate mais veemente do que durante a inflação de 1941 a 1948. Essa época foi extremamente turbulenta: as emprêsas se agitavam, a fim de preencher a procura do após-guerra e estavam lutando por novas posições no mercado; houve uma corrida para lançar novos produtos; os investimentos de capitais estavam sendo feitos num volume tremendo. A situação foi repleta de perdas e ganhos de capital resultantes das mudanças violentas na procura, na oferta e na estrutura de preços. A administração precisava da melhor espécie de informações, a fim de manter-se a par das condições e planejar eficientemente. A inflação levou os preços a aproximadamente o dôbro do seu nível de dez anos antes; tornou-se necessária uma revisão geral de idéias sôbre o valor de um dólar e o significado dos ativos mais antigos nos livros. Uma das consequiências significativas da inflação foi a controvérsia amarga entre contadores, advogados, economistas e políticos sôbre a verdade ou ficção da prática contábil dêsse período. A discussão foi uma troca de especulações sôbre obrigações legais ou morais a investidores, problemas de tributação, tradições contábeis estabelecidas, níveis tuturos de preços e conveniência política. Da controvérsia sairam demonstrações de lucros e perdas com um número de reservas especiais e notas explicativas, além de alguns tratamentos extraordinários de depreciação. (11)

(10) O ponto de vista de que a contabilidade não é essencialmente um processo de avaliação mas de apropriação de custos históricos, tem recentemente tido defensores de valor. Vide Accounting Review, vol. XI, n. ${ }^{9}$, junho de 1936, pg. 188. Vide também Accounting Research Bulletin n. ${ }^{\circ}$ 33, American Institute of Accountants, 14 de outubro de 1948.

(11) Entre os últimos, estavam a taxa aumentada de depreciação sôbre o custo original da «U. S. Steel», bem como a reavaliação para menos que fêz a «Chrysler», das aquisições de após-guerra, para o nível de custo do período anterior à guerra, antes do início dos lançamentos de depreciação. 
Estava implícito, na maioria das diretrizes de depreciação que, eventualmente, voltaríamos a preços do período anterior à guerra. Esta presunção parecia ser bastante irreal e irrelevante para a maioria dos economistas e era claro que as demonstrações de lucro publicadas tinham apenas começado a reconhecer a mudança básica no poder de compra do dólar. Com os preços num novo plano, os lançamentos de depreciação, em têrmos de preços do período anterior à guerra, representavam apenas aproximadamente a metade do financiamento das reposições de após-guerra, sendo quase impossível determinar que parte do "boom" de investimento de capitais estava realmente acrescentando à capacidade produtiva da nação.

As estatísticas de lucros de sociedades anônimas eram provàvelmente superestimativas brutas de lucros econômicos, (12) se bem que o montante da distorção fôsse difícil de estimar. Num período de inflação, o custo de vida sobe, tanto para as emprêsas, como para as pessoas. Sobem os custos de renovação dos estoques, de reposição do equipamento usado e de expansão da capacidade. Entretanto, as práticas contábeis geralmente falham em registrar adequadamente êstes aumentos. Quando os estoques e a depreciação são lançados aos custos originais, em vez de ao custo mais alto de reposição, o estoque e o ativo fixo são reavaliados à medida que são movimentados. A contabilidade ortodoxa evita cuidadosamente que as reavaliações ordinárias entrem na conta de lucros e perdas - tratando-as como ajustes de lucros suspensos. Porém, quando as reavaliações acham um meio indireto de chegar às contas, pelo processo de rotação de ativo durante a inflação, elas acabam também por chegar à conta de lucros e perdas. Estes lucros de reavaliação são tratados como lucros ordinários da emprêsa e não podem ser distinguidos, nos livros, de outros lucros. Assim, o lucro contábil superestima o lucro real da emprêsa, não sòmente durante a inflaçãn, mas também durante algum tempo depois que os preços tenham atingido estabilidade. E claro que não é sufi-

(12) Este ponto de vista foi geral e, indubitàvelmente, um dos fatôres que conservou baixos os preços de mercado das ações em relação aos lucros correntes declarados. 
ciente deflacionar o rendimento declarado, dividindo os lucros em dinheiro por qualquer índice de custo-de-vida, à semelhança do que é feito para se achar o salário real. Os lucros são o resíduo de um cálculo que usa dólares de datas muito diferentes - os dólares em dinheiro de hoje, os dólares do estoque do ano passado e os dólares do equipamento de muitos anos de prosperidade e depressão. Para medir os lucros reais, todos êstes ativos devem ser lançados em dólares com o mesmo poder de compra. Esta é uma operação trabalhosa, e os dados necessários de preços, produtos e datas são comumente difíceis de estimar. Com algumas simplificações, entretanto, podem ser feitas aproximações úteis. Com relação aos impactos do nível de preços, podem ser distinguidas três espécies de estimativas de lucros: (1) lucros em dólares de valores reais mistos de diversos anos; (2) lucros em dólares ao valor corrente; e (3) lucros em dólares de valor constante. Os lucros declarados pela contabilidade convencional são, como já vimos, uma mistura de dólares de diferentes datas e, comumente, de poder aquisitivo diverso.

\section{Lucros em Dólares ao Valor Corrente}

A segunda espécie pode ser estimada por meio de ajustes do nível de preços que fariam as receitas e custos, de um determinado ano, refletir o poder aquisitivo do dólar daquele ano. Isto remove muito da distorção causada por dólares de valor real diferente na mesma demonstração de lucros e perdas. As estimativas de lucros baseadas, cada ano, em dólares ao valor corrente, seriam diretamente utilizáveis para diversos propósitos da administração (por exemplo, avaliação do desempenho dos administradores da emprêsa). Serviriam, também, como passo intermediário na aproximação dos lucros em dólares de valor constante, uma vez que a deflação simples, análoga à da conversão de salários em dinheiro em "salárıs reais", seria legítima para fins práticos.

Os lucros em dólares de valor corrente são análogos aos que seriam dados pela contabilidade convencional para uma em- 
prêsa manutatureira que não tivesse ativo tangível, ou mesmo estoques. Supõe-se aqui que a companhia compra materiais apenas de acôrdo com as necessidades, aos preços correntes de mercado, e aluga equipamento por montantes que refletem contìnuamente o custo corrente de reposição do equipamento. Os lucros que são estimados pela aproximação desta situação de ausência de ativo representariam lucros de operação em dólares de valor corrente. Esta espécie de ajuste, não sòmente afasta as perdas e ganhos fictícios trazidos por flutuações nos níveis de preços, mas também revela alguns dos ganhos e perdas de capital mais permanentes, causados por mudanças nos preços relativos.

Para muitas emprêsas, os lucros em dólares de valor corrente podem ser aproximados por uma combinação de depreciação baseada no valor de reposição e no cálculo de custo de materiais pelo método "LIFO" - (último que entra - primeiro que sai). A depreciação em linha reta baseada no valor de reposição não ataca diretamente o problema, como já vimos, no sentido dos custos do promotor do negócio ou do desgaste do poder aquisitivo. Porém, a depreciação baseada no custo de reposição é satisfatória, se bem que não inteiramente. E preferível à depreciação de custo histórico para a maioria das decisões administrativas.

A contabilização do estoque pelo sistema "LIFO" pode, em períodos de inflação, ajudar a aproximar os lucros em dólares de valor corrente. É atualmente muito usada e pode ser qualificada como um método legítimo para avaliação de custo de materiais para fins de impôsto de renda. Pelo método "LIFO", os últimos materiais comprados são os primeiros lançados a custo da mercadoria vendida e, quando a rotação do estoque é baixa, o lucro da emprêsa é apurado com base em preços de materiais, mais recentes do que os usados no método "FIFO" (primeiro que entra - primeiro que sai). Quando os preços estão em ascensão, "LIFO" produz um lucro mais baixo do que "FIFO" (urna vez que os custos dos materiais debitados são mais baixos) e, quando os preços estão baixando, mostra um lucro mais elevado. "LIFO", assim, tende a eliminar os lucros contábeis que resultam da comparação de um estoque 
final com um estoque igual inicial declarado a preços diferentes.

Porém, a escolha entre "LIFO" e "FIFO" é ainda a escolha entre os métodos da contabilidade de custos históricos, e nenhum dêles atende completamente ao pedido do economista para uma avaliação a preços correntes de mercado. Num ano como o de 1946, em que houve uma elevação de preços acompanhada por expansão física de estoques, "LIFO" poderia dar, para o estoque final e o custo da mercadoria vendida com dólares de poder aquisitivo diferentes valores, tão confusos quanto aquêles produzidos por "FIFO". Além disso, quando os estoques estão sendo reduzidos, o custo da mercadoria vendida e os níveis de estoque começam a mostrar preços cada vez mais antigos e irrelevantes. Para atingir o ideal do realismo econômico, é necessário reavaliar inteiramente os estoques, a preços constantes.

Uma estimativa interessante do efeito da deflação de lucros em dólares de valor corrente (13) foi a de que a cifra de 50 bilhões de dólares para lucros totais de sociedades anônimas para 1946/1948 era 38\% fictícia. Dezenove bilhões foram, na realidade, lucros de estoque (isto é, aumento no valor em dólares de um estoque físico constante) mais subdepreciação (falha em lançar suficiente depreciação para fins de reposição).

\section{Lucros em Dólares de Valor Constante}

Entretanto, o estudo feito pelo MAPI, foi, na realidade, uma declaração incompleta da distorção total que havia ocorrido, uma vez que negligenciou as perdas de capital que a inflação tinha produzido no poder aquisitivo do ativo disponível. Isto é, se os preços subiram 50\% entre 1940 e 1947, um saldo bancário de um milhão de dólares, em 1947, valia apenas dois têrços do mesmo saldo em 1940, em têrmos daquilo que poderia comprar. Deveria, também, movimentar-se 50\% mais rápido para manter o mesmo ritmo de atividade. A perda

(13) Inflation and Postwar Profits, Machinery and Allied Products Institute, maio de 1949. 
ocorre em margens de segurança de liquidez. (14) Este e outros efeitos menos importantes poderiam ser incluídos numa estimativa completa da distorção dos lucros durante uma inflação.

As estimativas contábeis de lucro podem ser deflacionadas para dólares de valor constante por três métodos alternativos que diferem quanto à conceituação, bem como estatìsticamente. Êstes três métodos podem ser caracterizados como: deflação por meio de índices gerais de custos de reprodução; (2) deflação através de índices especiais de custos históricos; (3) deflação através de um índice único de custos históricos. O primeiro método, que é o mais caro e sofisticado dos três, é uma operação de duas etapas. Primeiro, tôdas as contas são lançadas novamente, a preços correntes, ano por ano, a fim de eliminar a confusão de dólares de poder aquisitivo diferente e a fim de considerar as mudanças de preços relativos que são causadas por alterações nos hábitos de compra do consumidor e nos custos de produção. Isto é conseguido através do ajuste individual de cada conta. A etapa seguinte dêste método é aplicar um índice geral de preços às contas ajustadas, que agora refletem custos de reprodução. Isto é feito a fim de tornar comparáveis, em poder aquisitivo, os dólares correntes de anos diferentes.

O primeiro método de deflação do lucro convencional da emprêsa vem ilustrado no Quadro I, que compara os três métodos analisados, aplicando-os a duas máquinas que foram adquiridas em datas diferentes, precedentes ao período-base de deflação. A linha $\mathrm{G}$ mostra os resultados do uso do primeiro

(14) Pode-se perguntar por que possuir dinheiro, durante a inflação, é considerado uma perda, uma vez que é também possível dizer que aquêle que possui bens materiais realiza um lucro em relação àquele que possui dinheiro. Esta é uma questão relativa e depende, parcialmente, da natureza da inflação. Se a inflação é causada por deprivação real, digamos, depois de um terremoto, aquêle que é proprietário de uma casa não danificada lucrou em relação à maioria das pessoas. Porém, quando a inflação é o resultado da espiral salários-preços, nada é destruído senão o valor do dinheiro e isto é, muito razoàvelmente, visto como uma perda relativa da habilidade dos proprietários e dos que percebem salários de comprarem bens de consumo. 
Q U A D R O I

ILUSTRAÇÃO DE TRESS MÉTODOS DE DEFLAÇÃO

(Dados Hipotéticos)

Data de aquisição
Dados de preços:

A. Custo histórico $\ldots \ldots \ldots \ldots \ldots$......
B. Custo de reposição no períodobase (por exemplo, 1936-

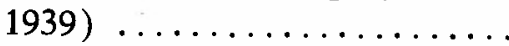

C. Custo de reposição no período corrente (por exemplo, abril de 1951) ....................

Nivel geral de preços:

D. Na data de aquisição ......

E. No período-base ............

F. No período corrente ........

Custo deflacionado:

G. Pelo primeiro método, defiação do custo corrente de reposição $\left[\left(A \div \frac{A}{C}\right) \div F\right]$

\begin{tabular}{|c|c|c|}
\hline Máquina $x$ & Maquina $Y$ & TOTAL \\
\hline 1938 & 1934 & \\
\hline$\$ 80$ & $\$ 60$ & $\$ 140$ \\
\hline 100 & 100 & 200 \\
\hline 150 & 200 & 350 \\
\hline 70 & 60 & \\
\hline 100 & 100 & \\
\hline 180 & 180 & \\
\hline $831 / 3$ & 111 & $194 \mathrm{1} / 3$ \\
\hline 100 & 100 & 200 \\
\hline 114 & 100 & 214 \\
\hline
\end{tabular}

H. Pelo segundo método, custo de reposição no período base $\left(A \div \frac{A}{B}\right)$

J. Pelo terceiro método, deflação do custo histórico $(A \div D) \ldots \ldots \ldots \ldots$ 
método com as máquinas $\mathrm{X}$ e $\mathrm{Y}$. A máquina $\mathrm{X}$, que custa 80 dólares em 1938, é lançada em têrmos do custo corrente de reprodução, por exemplo, de abril de 1951, ajustando os 80 dólares por meio de um número índice especial que mostra que custaria cêrca de 150 dólares para ser substituída agora. Este custo de reprodução é, então, deflacionado pelo índice corrente do nível geral de preços de abril de 1951, isto é, 180 dólares. O resultado é $831 / 3$ dólares. O mesmo processo usado para a máquina idêntica que foi comprada em época anterior e num nível mais baixo de preços, por exemplo, em 1934, produz um custo deflacionado diferente, ou seja, 111 dólares. O total da linha G, $1941 / 3$, representa o que as duas máquinas teriam custado em 1951 se o nível geral de preços permanecesse idêntico ao do período-base.

Esste processo trabalhoso é justificado sòmente com a premissa de que a estrutura de preços mostra, ano por ano, a lucratividade relativa que se espera de ativos de produtividade diferentes, tais como imóveis e maquinaria. A suposição implica em que os preços são completamente flexíveis e que não há nunca racionamento (tanto público quanto privado) de bens escassos, bem como capacidade em excesso para estoque em excesso. Porém, como sabemos, a rigidez de preços é bem generalizada no mundo real e, assim, os resultados desta deflação dão uma ilusão injustificável de precisão que não vale, geralmente, o custo de sua determinação. Uma segunda dificuldade, com êste método, é o problema clássico de achar um índice do "nível geral de preços". Na teoria econômica moderna o problema é, por sua natureza, insolúvel. Assim, mesmo o "nível de preços" aproximado tem significado sòmente quando se faz, na sua aplicação, uma presunção não-realística. (15) Porém, a despeito destas objeções teóricas, todos usam números índices e o problema prático é construir um que faça as suposições mais plausíveis sôbre os métodos de compra e tenha um mínimo de distorção do modêlo teórico de índice escolhido. O problema é suficientemen-

(15) Uma discussão recente do problema do número índice é encontrada em M. J. Ulmer, «Economic Theory of Cost of Living Index Numbers», Columbia University Press, New York, 1949. 
te difícil para um índice de consumidor em que o fim último do dinheiro é claro. Porém, o conceito de um custo-de-vida de emprêsa é matéria de especulação profunda que foi tocada apenas superficialmente nas discussões teóricas.

O segundo método alternativo, que é menos custoso mas mais difícil de racionalizar, é justificado pelas dificuldades surgidas da conceituação pura de deflação. Por êste método, o custo original é deflacionado por índices especializados. Assim, as mudanças nos preços relativos que são tão minuciosamente reconhecidas no primeiro método são deliberadamente eliminadas da estimativa do rendimento. Como resultado, tôdas as contas são declaradas em têrmos de seus preços durante o mesmo período-base, digamos, 1936/1939. A suposição, neste método, é de que a estrutura média de um período qualquer de razoável estabilidade é mais significativa que os preços relativos de qualquer data, como denominador comum para combinação de quantidades físicas de tijolos, aço e maquinaria. Estas quantidades físicas são tomadas para medir a verdadeira riqueza da companhia, sendo o problema do nível geral de preços claramente evitado. Assim, no quadro $\mathrm{I}$, as máquinas $\mathrm{X}$ e $\mathrm{Y}$ são lançadas aos custos reais durante o período-base, 100 dólares, em vez de, como no primeiro método, no que teriam custado êste ano, não tivesse o nível de preços mudado no período-base. Embora êste conceito afete as mudanças em produtos e tecnologia que o primeiro tenta captar, é consideràvelmente menos custoso para aplicar e não representa um esfôrço maior para a nossa credulidade. Como o primeiro, entretanto, é uma tentativa de medir o valor da propriedade em vez de seu custo.

O terceiro método, ainda mais barato, consiste em aplicar um índice único a todos os itens da conta, usando o nível de preços da data do lançamento. Êste método não reconhece os movimentos de preço de artigos especiais e apenas lança a perda ou ganho no poder aquisitivo geral, incorrido ao tempo em que as diversas transações foram levadas a cabo. É, assim, um registro de custo histórico lançado em dólares de valor constante. Quaisquer que sejam os usos que tenha, êstes dependem da utilidade de qualquer registro de custos 
históricos. (16) Na ilustração do quadro I, o custo original das máquinas é deflacionado pelo índice geral de preços da data em que foram compradas, a fim de mostrar o que teriam custado, naquele tempo, se os preços em geral tivessem estado no nível do período-base.

$\mathrm{Na}$ prática, a verdadeira escolha de métodos de deflação se situa entre o segundo e o terceiro métodos. O primeiro é eliminado devido ao seu alto custo, sua pouca plausibilidade e a dificuldade de estabelecer custos de reposição para maquinaria velha. O segundo método recebe forte apoio devido ao nosso conhecimento dos diversos aspectos em que a prática de preços difere da teoria de preços, na concorrência. As grandes diferenças no comportamento de preços para produtos diferentes, na última década, podem ser explicadas muito melhor em têrmos de estruturas de concorrência de tipos diferentes do que por diferenças na procura por parte do consumidor. O problema importante, no segundo método, é escolher um período-base significativo. A virtude única do terceiro é a sua simplicidade, que pode compensar, pelo menos em comparações de períodos curtos, as imprecisões que apresenta.

A segunda espécie de deflação total a têrmos reais foi aplicada pelo autor a três dos maiores fabricantes de produtos elétricos, para o período de 1935 a 1947 . Todo o ativo foi lançado em têrmos de seu nível de preços de 1935, por meio da deflação de cada grupo principal de ativos através de um índice adequado de preços. As mudanças no ativo líquido total da companhia, de um fim-de-ano a outro fim-de-ano, mais dividendos, menos novos fundos de capital (também lançados em dólares ao valor de 1935), dão uma medida dos seus lucros reais. Esste método de estimar os lucros reais eliminou das contas os lucros causados pela inflação dos valores em dólares dos estoques que nada significavam em têrmos reais; eliminou a expansão aparente de alguns dos ele-

(16) Um estudo bem conhecido de deflação por meio de um índice único é o de R. C. Jones, «Effective Inflation on Capital and Profits: Record of Nine Steel Companies», Journal of Accountancy, janeiro de 1949. 
mentos do ativo imobilizado que refletiam meramente o elevado custo do equipamento; revelou a perda em valor real do ativo em dinheiro. (17)

Os resultados do estudo aparecem no Quadro II. Ali, o lucro agregado é pôsto em contraste com o mesmo lucro, quando declarado em dólares de poder aquisitivo constante, e com os lucros reais deduzidos pelo processo de deflação total. A diferença entre o curso aparente e real dos acontecimentos é notável; é o resultado do longo e contínuo aumento no nível de preços. A alta de preços, de junho de 1946 até fins de 1947, é refletida na grande diferença entre o lucro declarado e deflacionado para 1947. A disparidade varia de companhia para companhia, de acôrdo com as diretrizes diversas de cada uma com referência a numerário, estoque e desembolsos para investimento em ativo fixo do período de após-guerra; mas para os fabricantes dêste tipo de artigos em geral, a tendência do comportamento de lucros mostrada no quadro II é mais ou menos típica.

Esta deflação de lucros não é uma demonstração completa do conceito econômico do rendimento para estas companhias. Ela ajusta as cifras contábeis sòmente para mudanças no nível de preços e não para ganhos e perdas de capital em têrmos de bens atuais. (18) A estimativa do lucro, repetimos, é essencialmente um problema de previsão, um esfôrço

(17) Uma análise desta natureza levanta diversos problemas de metodologia que não podem ser discutidos aqui, em pormenor. Os mais importantes dentre êles são: (1) a escolha de índices apropriados de preços; (2) a escolha de um período-base para os índices, que reflita adequadamente a idéia do analista da relação «normal» de preços entre os vários tipos; e (3) o grau de refinamento que parece ser necessário na deflaçāo individual das contas do ativo, levando-se em consideração que os índices de preço têm apenas aplicabilidade geral em relação às propriedades de poucas companhias selecionadas. As três companhias estudadas foram a «General Electric Co.», a «Westinghouse Electrical and Manufacturing Co.» e a «Radio Corporation of America».

(18) o primeiro método de deflação descrito, deflação de custos de reprodução, dá um ajuste parcial para perdas e ganhos de capital, mas não inclui, naturalmente, avaliações para menos do ativo que não vale a pena substituir. 
para evitar as surprêsas que aparecem na forma de ganhos e perdas de capital. Os ajustes de preços constituem um refinamento das estimativas contábeis. O resultado, porém, continua a ser uma conjetura baseada em indicações de valor secundárias, isto é, nas quantidades de ativo tangível. (19)

\section{Impacto nas Decisões Administrativas}

O importante papel desempenhado pelas estimativas de lucros nas decisões administrativas justifica as críticas feitas às práticas aceitas de contabilidade, na apuração de lucros. (20) Em geral, a espécie de apuração de lucro necessária para a maioria das decisões administrativas está mais próxima do ideal do economista do que da prática do contador. Sem uma compreensão dêstes conflitos entre as convenções da contabilidade e a análise econômica, há o perigo de que os lucros contábeis influirão no raciocínio administrativo em áreas que estão além do seu domínio. A contabilidade é destinada a fins especiais da análise financeira e à codificação de leis públicas e administração de impostos. As conseqüências legais da contabilidade são tão importantes, que se exigem, da prática contábil, grande uniformidade e acôrdo geral.

Porém, levar estas exigências de exatidão à análise geral econômica destinada a informar as diretrizes administrativas, significa, muitas vêzes, obscurecer a verdadeira natureza de uma situação altamente incerta. Além disso, pode facilmente confundir uma administração menos sofisticada no tocante às relações da contabilidade com a realidade econômica.

(19) Para uma discussão dêste ponto, vide J. B. Canning, Economics of Accounting, páginas 231-232.

(20) Os contadores não estão, absolutamente, desavisados em relação a êstes problemas. Um resumo dos pontos cruciais da questão, com um pedido de pensamento mais flexível por parte dos contadores em face das mudanças importantes de preços, pode ser encontrado em G. O. May, Business Income and Price Levels - An Accounting Study. American Institute of Accountants, julho de 1949. 


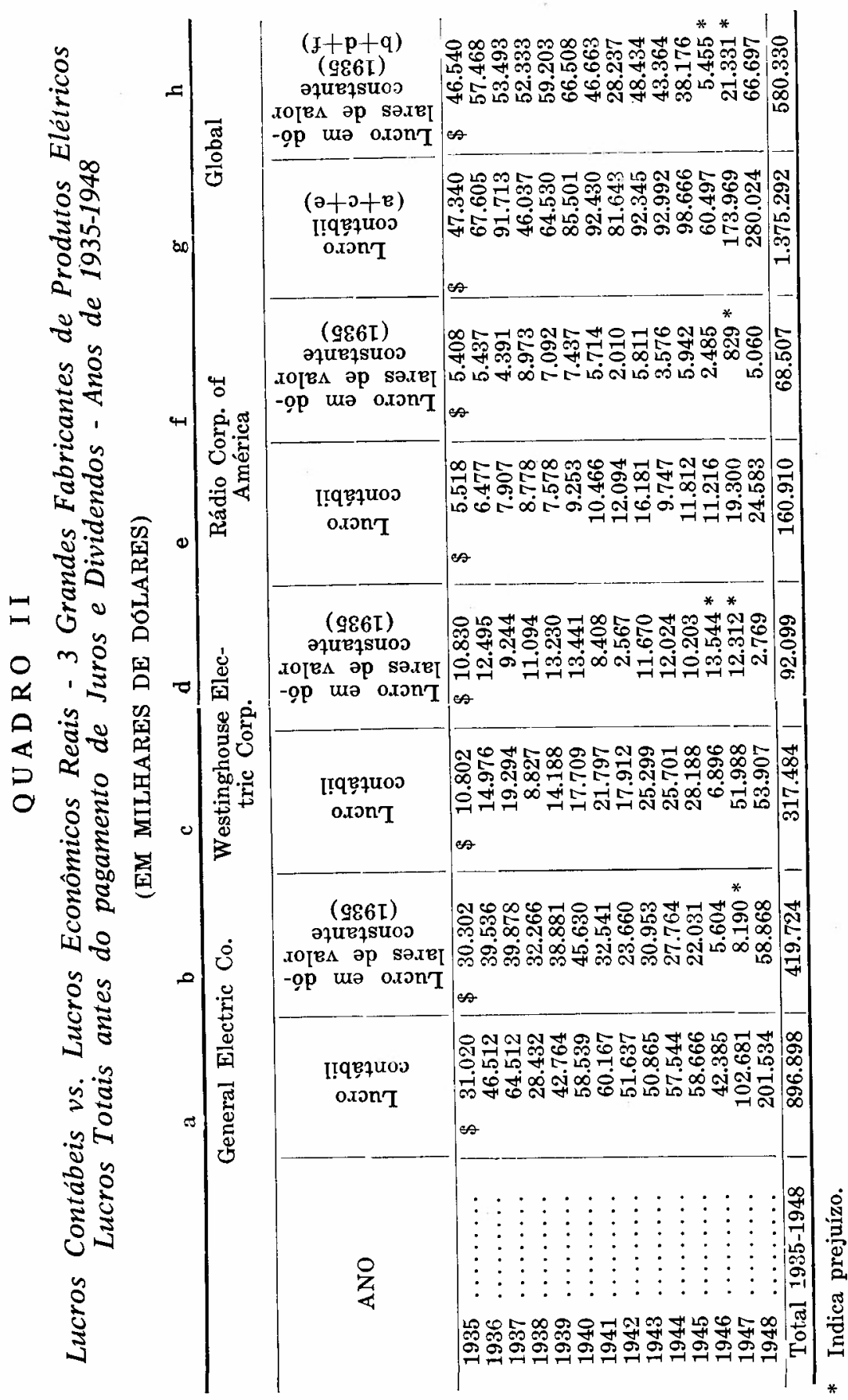




\section{Conclusões}

Ao invés de nos juntarmos à condenação feita às emprêsas por terem dois grupos de livros, esta análise sugere que a emprêsa necessita, nestes discutidos tempos de elevação do nível de preços, de três ou mais conjuntos de livros, a fim de fazer: (1) a declaração do lucro para fins fiscais; a declaração do lucro computado pelos processos contábeis convencionais; (3) a declaração do lucro deflacionado para dólares de poder aquisitivo constante.

A falha básica das demonstrações contábeis para fins de análise econômica é que a contabilidade é, como está implícito no seu nome, um registro histórico, ao passo que os problemas econômicos da administração têm a ver com o futuro. Como resultado, as idéias econômicas de lucro, ativo e patrimônio líquido são medidas pelos relatórios financeiros convencionais. Seria, entretanto, êrro tentar adaptar a contabilidade financeira a conceitos econômicos. Os problemas da administração tomam inúmeras formas; um sistema contábil que servisse a tôdas elas é difícil de conceber. Ao contrário, as contas deveriam ser tidas como fonte de dados históricos básicos que podem ser ajustados e combinados de diferentes maneiras, para diferentes necessidades. 